\title{
Association between low-frequency ultrasound and hip fractures - comparison with DXA-based BMD
}

Mikko Määttä ${ }^{1,2^{*}}$, Petro Moilanen ${ }^{3}$, Jussi Timonen ${ }^{3}$, Pasi Pulkkinen' ${ }^{1}$, Raija Korpelainen ${ }^{1,4,5,6}$ and Timo Jämsä1,6,7

\begin{abstract}
Background: New methods for diagnosing osteoporosis and evaluating fracture risk are being developed. We aim to study the association between low-frequency (LF) axial transmission ultrasound and hip fracture risk in a population-based sample of older women.

Methods: The study population consisted of 490 community-dwelling women (78-82 years). Ultrasound velocity $\left(V_{\text {LF }}\right)$ at mid-tibia was measured in 2006 using a low-frequency scanning axial transmission device. Bone mineral density (BMD) at proximal femur measured using dual-energy $x$-ray absorptiometry (DXA) was used as the reference method. The fracture history of the participants was collected from December 1997 until the end of 2010. Lifestyle-related risk factors and mobility were assessed at 1997.

Results: During the total follow-up period (1997-2010), 130 women had one or more fractures, and 20 of them had a hip fracture. Low $V_{\mathrm{LF}}$ (the lowest quartile) was associated with increased hip fracture risk when compared with $V_{L F}$ in the normal range (Odds ratio, $O R=3.3,95 \%$ confidence interval $(C l)$ 1.3-8.4). However, $V_{L F}$ was not related to fracture risk when all bone sites were considered. Osteoporotic femoral neck BMD was associated with higher risk of a hip fracture $(\mathrm{OR}=4.1,95 \% \mathrm{Cl} 1.6-10.5)$ and higher risk of any fracture $(\mathrm{OR}=2.4,95 \% \mathrm{Cl} 1.6-3.8)$ compared to the non-osteoporotic femoral neck BMD. Decreased $V_{\mathrm{LF}}$ remained a significant risk factor for hip fracture when combined with lifestyle-related risk factors ( $\mathrm{OR}=3.3,95 \% \mathrm{Cl}$ 1.2-9.0).
\end{abstract}

Conclusion: Low $V_{\mathrm{LF}}$ was associated with hip fracture risk in older women even when combined with lifestyle-related risk factors. Further development of the method is needed to improve the measurement precision and to confirm the results.

Keywords: Quantitative ultrasound, Speed of sound, Osteoporosis, Hip fracture, Cortical bone

\section{Background}

Osteoporotic fractures possess a significant public health problem that is increasing due to aging population. At the moment, the golden standard used in fracture risk assessment is bone mineral density (BMD) measurements using dual energy $x$-ray absorptiometry (DXA). Recently, World Health Organization (WHO) introduced FRAX, a fracture risk calculator that combines easily obtained clinical information and DXA-based femoral neck BMD, if

\footnotetext{
* Correspondence: mikko.maatta@hiphealth.ca

'Department of Medical Technology, University of Oulu, Institute of Biomedicine, PO Box 5000, Fl-90014 Oulu, Finland

${ }^{2}$ Infotech Oulu, University of Oulu, Oulu, Finland

Full list of author information is available at the end of the article
}

available, to estimate the 10-year osteoporotic fracture probability [1].

Quantitative ultrasound (QUS) has raised interest as an alternative method to $\mathrm{x}$-ray-based imaging for measuring bone status. There is a number of different QUS methods that have been used to assess bone status and to evaluate fracture risk [2]. The advantages of ultrasound include a relatively low cost and a portable technique with no ionizing radiation. The results of QUS measurements have been shown to be associated with fracture risk [3]. A question has arisen whether QUS parameters can serve as a surrogate for DXA-based BMD to improve FRAX estimate [4].

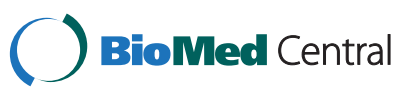

(c) 2014 Määttä et al.; licensee BioMed Central Ltd. This is an Open Access article distributed under the terms of the Creative Commons Attribution License (http://creativecommons.org/licenses/by/2.0), which permits unrestricted use, distribution, and reproduction in any medium, provided the original work is properly credited. 
A novel low-frequency (LF) axial transmission QUS method for assessing the properties of cortical bone has been shown to reflect bone density and cortical thickness [5-7]. A relationship between the LF tibial velocity $\left(\mathrm{V}_{\mathrm{LF}}\right)$ and geometry of proximal femur in older women has also been suggested [8]. However, the suitability of the method for individual fracture risk assessment has not yet been established.

In this study we evaluated the association between the LF axial transmission ultrasound method and fractures in a population-based sample of older women, using the standard DXA as the reference method. We hypothesized that decreased ultrasound velocity measured on tibia is associated with increased hip fracture risk in elderly females. In our previous population based prospective study we assessed life-style related determinants of hip fracture in elderly females [9]. Here we analyzed how the combination of low-frequency ultrasound and previously determined lifestyle-related factors are related to the risk of hip fracture.

\section{Methods}

\section{Subjects and clinical assessment}

The study population consisted of 490 women born between 1924 and 1927, originally recruited in 1997 as a population-based cohort to study the risk factors for osteoporosis and fractures [10]. All those still alive belonging to the original cohort were invited to clinical measurements in 2006. A total of 618 women attended these measurements, and 490 were measured using quantitative ultrasound. The fracture history between December 1, 1997 and December 31, 2010 was collected from hospital discharge registers. The fractures were confirmed manually from medical records to avoid the bias of recording multiple hospitalizations due to a single fracture. Health and lifestyle information, including medical history, age at menopause, smoking habits, alcohol and coffee consumption, physical activity and mobility, calcium and vitamin D intakes, and fracture history was collected at study baseline in 1997 using self-administrative questionnaires and interviews. The assessment of functional mobility at baseline was done using the "Timed Up \& Go" (TUG) test [11]. All subjects gave a written informed consent and the study protocol was approved by the Ethics Committee of the Northern Ostrobothnia Hospital District. The study was done in accordance with the Declaration of Helsinki.

\section{Quantitative ultrasound measurements}

The speed of sound was recorded in the medial mid-shaft of the left tibia using a scanning low-frequency (LF) axial transmission device. The principle of the device and the measurement setup has been published previously $[7,8]$. In brief, two separate transducers $\left(f_{c}=200 \mathrm{kHz}\right)$ mounted on a rail scanned a $30 \mathrm{~mm}$ distance. The time of flight of the first arriving signal (FAS) was determined using the first maximum. The apparent velocity of the FAS $\left(\mathrm{V}_{\mathrm{LF}}\right)$ was determined by measuring the time of flight for a number of source-receiver distances. The precision error was characterized by CVrms which was $3.2 \%$. The standardized coefficient of variation (SCV) [12] of the method was $6.6 \%$. Due to the lack of established reference population data, we used the present study population to define the range of $\mathrm{SCV}$.

\section{DXA measurements}

A Hologic DXA device (Delphi QDR series, Hologic, Bedford, MA, USA) was used to get the reference data. Standard anteroposterior positioning was used to measure the femoral neck bone mineral density (BMD) of the left proximal femur.

\section{Statistical analysis}

The subjects of the study were divided into three groups based on their fracture history (Figure 1): a) women without fractures (NF, controls), b) women with any fracture $(\mathrm{Fx})$, and c) women with a hip fracture (Hip Fx). All the hip fracture patients were also included in group (b). The fracture data of three different time periods were analyzed: a) from the beginning of the follow-up period until the time of bone measurements (1997-2006), b) from the time of the bone measurements until the end of the follow-up period (2006-2010), and c) the whole follow-up period (1997-2010). The women with fractures were compared to those without fractures. Since the data were normally distributed the independent samples $t$-test was used to analyze the statistical significance of the differences between the NF, Fx, and Hip Fx groups. The study subjects were also classified in to normal, osteopenic, and osteoporotic according to their femoral neck BMD Tscore in accordance with the WHO definition [13]. Due to the lack of an established reference population, T-scores could not be calculated for low-frequency ultrasound velocity $\left(\mathrm{V}_{\mathrm{LF}}\right)$. Thus, $\mathrm{V}_{\mathrm{LF}}$ results were divided into three groups based on quartiles within the study population: a) low $\mathrm{V}_{\mathrm{LF}}(0-25 \%)$, b) moderate $\mathrm{V}_{\mathrm{LF}}(25-50 \%$ and $50-75 \%$ combined), and c) high $\mathrm{V}_{\mathrm{LF}}(75-100 \%)$. Crosstabulation and the $\chi^{2}$ test were used to compare the distribution of the subjects with fractures and those without fractures within these groups. To further analyze the statistical significance of the association of bone measurement results (QUS/DXA) with the fracture risk, a multivariate logistic regression analysis was used. The results of those analyses are reported as the odds ratios (OR) and 95\% confidence intervals (CI). The imaging modality (QUS/DXA) used was included in the model and the forward stepwise (likelihood ratio) method was used to form the final models. All models were adjusted with age and BMI. For the fractures that occurred after the measurements in 2006, the 


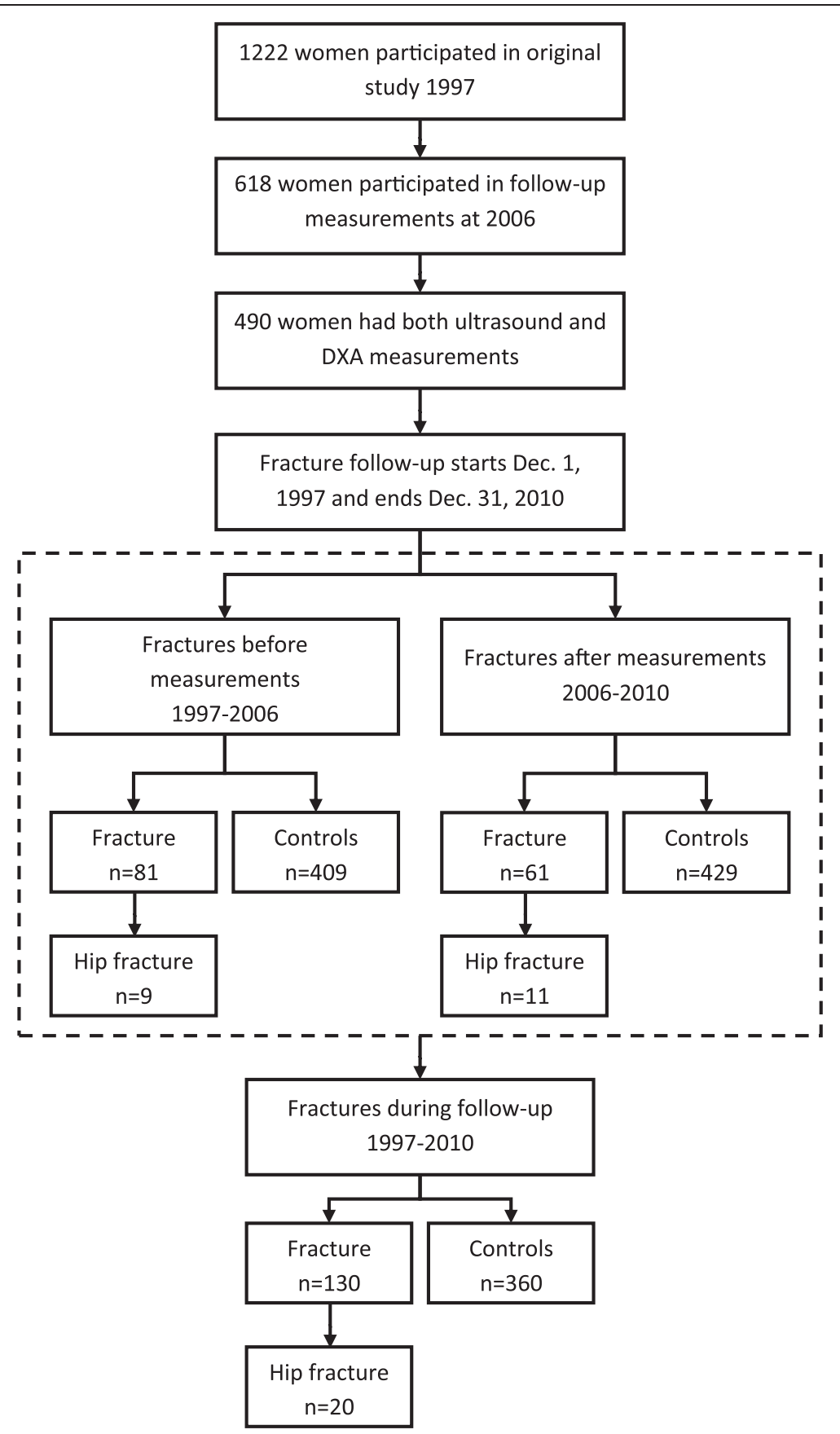

Figure 1 Consort chart. Number of women with and without fractures at different timepoints.

predictive ability of each bone measurement value was assessed using the Cox proportional hazards model and the corresponding hazard ratios (HR), and the 95\% CIs were calculated. A similar protocol to logistic regression was used. In addition, previous fractures (1997-2006) (yes, no) was added to models as covariates. The followup time between the measurement time and the time of the first fracture, death, or end of the follow-up period was recorded. Logistic regression models were also calculated to analyze the effect of combining $\mathrm{V}_{\mathrm{LF}}$ and previously determined [9] lifestyle-related risk factors for hip fracture. In our previous population based cohort study BMI, functional mobility, physical activity, hypertension, coffee consumption, and daily smoking predicted hip fractures in 1222 old women. These factors were used as a covariates to determine the best fit model for the current subpopulation with ultrasound and DXA measurements. 
Table 1 Distribution of fractures ( $(\%)$ ) according to the ICD-10 code with selected subdivisions in a population-based sample of older women $(n=490)$

\begin{tabular}{|c|c|c|c|c|}
\hline & & 1997-2006 & $2006-2010$ & 1997-2010 \\
\hline M80 & Osteoporosis with pathological fracture & & $2(2.6)$ & $2(1.1)$ \\
\hline S12 & Fracture of neck & & $1(1.3)$ & $1(0.6)$ \\
\hline S22 & Fracture of rib(s), sternum and thoracic spine & $3(3.1)$ & $3(3.9)$ & $6(3.4)$ \\
\hline S32 & Fracture of lumbar spine and pelvis & & & \\
\hline \multirow[t]{2}{*}{ S32.0 } & Fracture of lumbar vertebra & & $9(11.8)$ & $9(5.2)$ \\
\hline & Other & $3(3.1)$ & $4(5.3)$ & $7(4.0)$ \\
\hline S42 & Fracture of shoulder and upper arm & $11(11.2)$ & $6(7.9)$ & $17(9.8)$ \\
\hline S52 & Fracture of forearm & & & \\
\hline \multirow[t]{2}{*}{ S52.5 } & Fracture of lower end of radius & $29(29.6)$ & $22(28.9)$ & $51(29.3)$ \\
\hline & Other & $5(5.1)$ & $1(1.3)$ & $6(3.4)$ \\
\hline S62 & Fracture at wrist and hand level & $7(7.1)$ & $5(6.6)$ & $12(6.9)$ \\
\hline S72 & Fracture of femur & & & \\
\hline S72.0 & Fracture of neck of femur & $4(4.1)$ & $7(9.2)$ & $11(6.3)$ \\
\hline S72.1 & Pertrochanteric fracture & $1(1.0)$ & $4(5.3)$ & $5(2.9)$ \\
\hline \multirow[t]{2}{*}{ S72.2 } & Subtrochanteric fracture & $4(4.1)$ & & $4(2.3)$ \\
\hline & Other & $3(3.1)$ & $6(7.9)$ & $9(5.2)$ \\
\hline S82 & Fracture of lower leg, including ankle & $26(26.5)$ & $5(6.6)$ & $31(17.8)$ \\
\hline S92 & Fracture of foot, except ankle & $2(2.0)$ & $1(1.3)$ & $3(1.7)$ \\
\hline \multicolumn{2}{|c|}{ Total number of fractures } & $98(100)$ & $76(100)$ & $174(100)$ \\
\hline
\end{tabular}

ICD-10 = International Classification of Diseases, $10^{\text {th }}$ revision. Time periods represent previous fractures (1997-2006) and future fractures (2006-2010) with respect to the bone measurements, and all fractures during the follow-up period (1997-2010).

Table 2 Characteristics of the women with different fracture status (NF, Fx, and Hip Fx) in different time periods (1997-2006, 2006-2010, and 1997-2010) at the time of the measurements $(2006)(n=490)$

\begin{tabular}{|c|c|c|c|c|c|}
\hline & \multirow[t]{3}{*}{$\begin{array}{c}\text { NF } \\
n=360\end{array}$} & \multicolumn{2}{|c|}{ 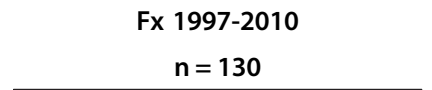 } & \multicolumn{2}{|c|}{$\begin{array}{l}\text { Hip Fx 1997-2010 } \\
n=20\end{array}$} \\
\hline & & Fx 1997-2006 & Fx 2006-2010 & Hip Fx 1997-2006 & Hip Fx 2006-2010 \\
\hline & & $\mathrm{n}=\mathbf{8 1}$ & $n=61$ & $\mathrm{n}=9$ & $n=11$ \\
\hline \multirow[t]{2}{*}{ Age [years] } & $79.9(1.2)$ & \multicolumn{2}{|c|}{$80.0(1.2)$} & \multicolumn{2}{|c|}{$80.0(1.3)$} \\
\hline & & $79.7(1.2)$ & $80.3(1.1)^{*}$ & $79.3(1.4)$ & $80.5(0.9)$ \\
\hline \multirow[t]{2}{*}{ Weight [kg] } & $67.7(11.3)$ & \multicolumn{2}{|c|}{$67.8(12.2)$} & \multicolumn{2}{|c|}{$69.8(15.7)$} \\
\hline & & $69.5(12.3)$ & $65.8(12.2)$ & $75.7(10.2)^{*}$ & $65.0(18.2)$ \\
\hline \multirow[t]{2}{*}{ Height [cm] } & $155.2(5.4)$ & \multicolumn{2}{|c|}{$155.6(5.8)$} & \multicolumn{2}{|c|}{$158.9(7.2)^{*}$} \\
\hline & & $156.6(5.4)^{*}$ & $154.5(6.4)$ & $160.7(4.4)^{*}$ & $157.4(8.8)$ \\
\hline \multirow[t]{2}{*}{ BMI $\left[\mathrm{kg} / \mathrm{m}^{2}\right]$} & $28.1(4.5)$ & \multicolumn{2}{|c|}{$28.0(4.7)$} & \multicolumn{2}{|c|}{$27.4(4.6)$} \\
\hline & & $28.4(4.8)$ & $27.5(4.6)$ & $29.3(3.6)$ & $25.9(4.9)$ \\
\hline \multirow[t]{2}{*}{$V_{L F}[\mathrm{~m} / \mathrm{s}]$} & $3583(193)$ & \multicolumn{2}{|c|}{$3547(200)$} & \multicolumn{2}{|c|}{$3515(245)$} \\
\hline & & $3534(204)^{*}$ & $3564(203)$ & $3500(291)$ & $3527(215)$ \\
\hline \multirow[t]{2}{*}{ Femoral neck BMD $\left[\mathrm{g} / \mathrm{cm}^{2}\right]$} & $0.654(0.102)$ & \multicolumn{2}{|c|}{$0.606(0.083)^{*}$} & \multicolumn{2}{|c|}{$0.589(0.102)^{*}$} \\
\hline & & $0.609(0.078)^{*}$ & $0.605(0.096)^{*}$ & $0.611(0.089)$ & $0.570(0.112)^{*}$ \\
\hline
\end{tabular}

Values are Mean (SD).

${ }^{*}$ Independent samples $t$-test $\mathrm{p}$-value $<0.05$ when compared to NF group. 
Table 3 The distribution of women with and without a fracture and hip fracture according to the $\mathrm{V}_{\mathrm{LF}}$ and $\mathrm{BMD}$ values

\begin{tabular}{|c|c|c|c|c|}
\hline & & $\begin{array}{c}\text { NF } \\
(n=360)\end{array}$ & $\begin{array}{l}\text { Fx } 1997-2010 \\
\quad(n=130)\end{array}$ & $\begin{array}{c}\text { Hip Fx } \\
1997-2010 \\
(n=20)\end{array}$ \\
\hline \multirow[t]{3}{*}{$V_{L F}$} & Highest 25\% & $101(28)$ & $24(18)$ & $5(25)^{*}$ \\
\hline & $25 \%$ to $75 \%$ & $170(47)$ & $69(53)$ & $5(25)$ \\
\hline & Lowest 25\% & $89(25)$ & $37(28)$ & $10(50)$ \\
\hline \multirow{3}{*}{$\begin{array}{l}\text { Femoral } \\
\text { neck BMD }\end{array}$} & Normal & $73(20)$ & $11(8)^{*}$ & $2(10)^{*}$ \\
\hline & Osteopenic & $206(57)$ & $65(50)$ & $8(40)$ \\
\hline & Osteoporotic & $81(23)$ & $54(42)$ & $10(50)$ \\
\hline
\end{tabular}

Values are $\mathrm{n}(\%)$. "Distribution of the group is different than that of the NF group ( $p$-value of $x^{2}$ test $<0.05$ ).

Statistical analyses were done using SPSS for Windows (Release 18.0, SPSS Inc., Chicago, IL, USA). In all tests, p-values less than 0.05 were considered statistically significant.

\section{Results}

During the first follow-up period (1997-2006), 98 fractures occurred in 81 women (Figure 1, Table 1). Between 2006 and 2010, 61 subjects sustained fractures; in total 76 different fractures occurred. Altogether, between the years 1997 and 2010, 174 different fractures occurred in 130 subjects. Wrist fracture was the most common fracture $(\mathrm{n}=51)$. There were 9 hip fractures between 1997 and 2006, and 11 hip fractures after the 2006 measurements, totaling in 20 hip fractures during the whole follow-up period. Thirty-five subjects died during the follow-up period.

The characteristics of different fracture groups are shown in Table 2. The women with a hip fracture were taller than the women without fractures $(\mathrm{p}<0.05)$. Those with a previous fracture (1997-2006) had a lower $V_{\mathrm{LF}}$ than the ones without fractures $(\mathrm{p}<0.05)$. Subjects who sustained a fracture during the follow-up period had a lower femoral neck BMD than those in the NF group $(\mathrm{p}<0.05)$, except when comparing the Hip Fx 1997-2006 and NF groups.

Differences between distributions in the NF and Hip Fx groups were observed in both $\mathrm{V}_{\mathrm{LF}}$ and femoral neck BMD ( $<$ 0.05) (Table 3). Also, there was a difference in the distribution of subjects based on femoral neck BMD between the Fx and NF groups.

Based on the regression analysis, low $\mathrm{V}_{\mathrm{LF}}$ was not associated with previous fractures (1997-2006) or with the fractures that occurred after the measurements (20062010) (Table 4). Decreased femoral neck BMD, however, was associated with increased fracture risk in all followup periods; estimated risks (odds and hazard ratios) varied between 1.8 and 2.5 compared to the women with femoral neck T-score $>-2.5$.

Decreased $\mathrm{V}_{\mathrm{LF}}$ was associated with an increased risk of hip fracture occurred before the measurements (19972006) $(\mathrm{OR}=6.3$; Table 5). Additionally, across the whole follow-up period (1997-2010), low $\mathrm{V}_{\mathrm{LF}}$ was associated with higher risk of hip fracture compared to moderate or high $\mathrm{V}_{\mathrm{LF}}(\mathrm{OR}=3.3)$. An osteoporotic femoral neck BMD predicted hip fractures after the measurements (2006-2010) with a hazard ratio (HR) of 4.8 (95\% CI 1.4-16.6) for subjects with a T-score $\leq-2.5$ compared to the women with normal or osteopenic T-score. Low femoral neck BMD was also associated with an increased risk of hip fracture $(\mathrm{OR}=4.1,95 \%$ CI 1.6-10.5) during the whole follow-up period (1997-2010) compared to women with normal or osteopenic femoral neck BMD. When $V_{L F}$ was combined with previously assessed [9] hip fracture risk factors regression model for the same population (Table 6), the final model included $V_{L F}$, low physical activity, and impaired functional mobility $(\mathrm{p}=$ 0.001, Table 6), $V_{L F}$ being the strongest independent factor for hip fracture (OR $=3.3,95 \%$ CI 1.2-9.0). Femoral neck BMD did not reach statistical significance when included in the regression analyses along with lifestylerelated risk factors.

Table 4 Association of low $\mathrm{V}_{\mathrm{LF}}$ and osteoporotic femoral neck BMD with fractures that occurred during different follow-up periods

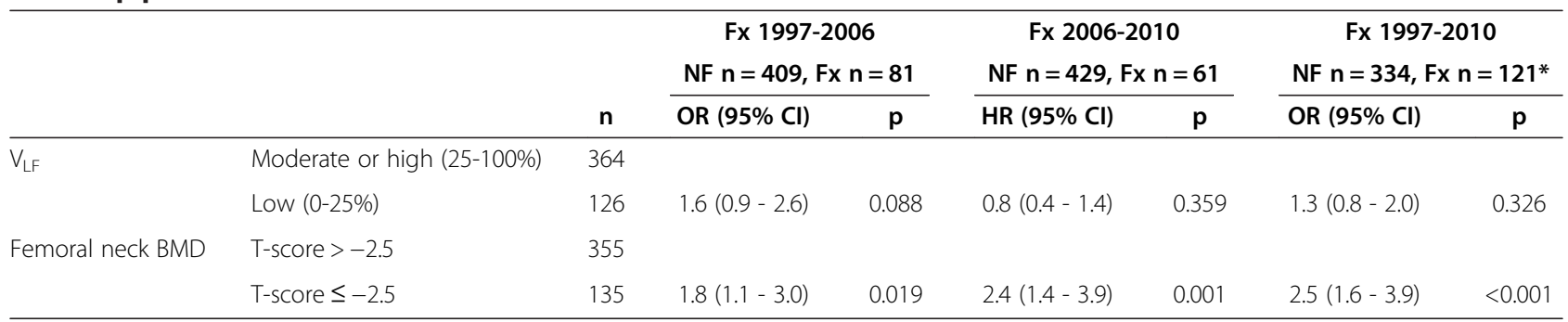

All regression models were adjusted by age and BMI. In Cox regression previous fracture (during 1997-2006) was also used as a covariate. NF $=$ non-fractured group, $\mathrm{Fx}=$ fractured group, $\mathrm{n}=$ number of subjects, $\mathrm{OR}=$ odds ratio of logistic regression, $\mathrm{HR}=$ hazard ratio of $\mathrm{Cox}$ regression, $\mathrm{Cl}=\mathrm{confidence}$ interval, $\mathrm{p}=\mathrm{p}$-value of the covariate in the model. *Subjects who died during the follow-up were excluded (NF $n=26, F x n=9$ ). 
Table 5 Association of low $\mathrm{V}_{\mathrm{LF}}$ and osteoporotic femoral neck BMD with hip fractures that occurred during different follow-up periods

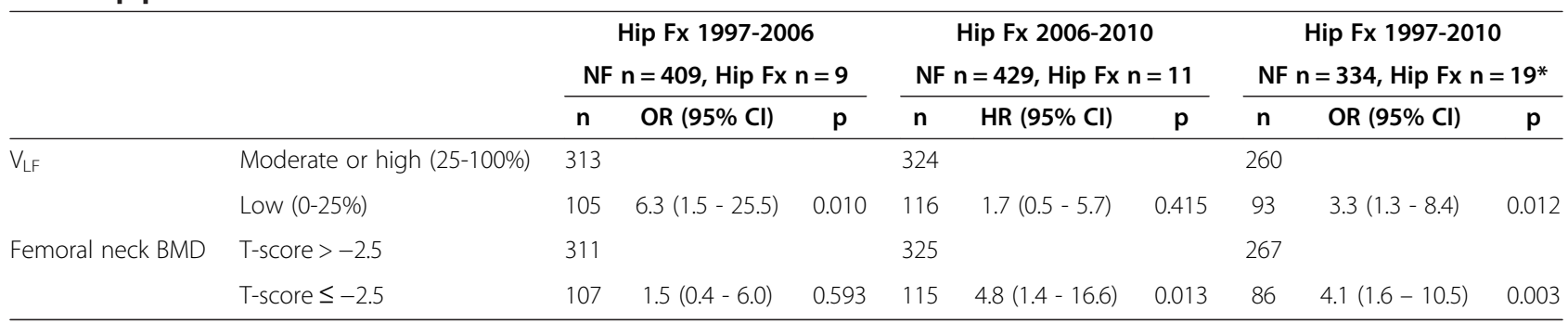

All regression models were adjusted by age and BMI. In Cox regression previous fracture (during 1997-2006) was also used as a covariate. NF $=$ non-fractured group, Hip $\mathrm{Fx}=$ hip fracture group, $\mathrm{n}=$ number of subjects, $\mathrm{OR}=$ odds ratio of logistic regression, $\mathrm{HR}=$ hazard ratio of $\mathrm{Cox}$ regression, $\mathrm{Cl}=$ confidence interval, $\mathrm{p}=\mathrm{p}$-value of the covariate in the model. *Subjects who died during the follow-up were excluded $(\mathrm{NF} n=26, \mathrm{Hip} F \mathrm{n}=1)$.

\section{Discussion}

In this population-based study, we used a low-frequency ultrasound scanner to assess the association between decreased ultrasound velocity and fracture risk. To our knowledge, this is the first time that low-frequency axial transmission ultrasound is being used in a populationbased cohort of older women. The reported results show that decreased ultrasound velocity $\left(\mathrm{V}_{\mathrm{LF}}\right)$ was associated with higher risk of hip fracture compared to moderate or high $\mathrm{V}_{\mathrm{LF}}$. DXA and LF ultrasound yielded similar results when comparing the hip fracture and non-fracture groups.

Our findings are in line with earlier studies on the fracture-discrimination ability of similar axial transmission ultrasound devices. Using the Omnisense (Sunlight, BeamMed Ltd, Petah Tikva, Israel) device, operating at a center frequency of 1.25 MHz, Nguyen et al. [14] reported that decreased tibial SOS is associated with increased fracture risk independently of BMD and age with an odds ratio (OR) of 1.75. The corresponding OR as determined for

Table 6 Logistic regression models without and with $\mathbf{V}_{\mathrm{LF}}$ for having a hip fracture in a population-based sample of older women

\begin{tabular}{lccc}
\hline & OR & $\mathbf{( 9 5 \% ~ C l )}$ & p-value \\
\hline Lifestyle-related risk factors $^{1}$ & & & $0.002^{*}$ \\
TUG $\geq 11$ s vs. less (referent) & 3.4 & $(1.2-9.9)$ & 0.026 \\
Low PA vs. moderate to high (referent) & 2.8 & $(1.0-7.5)$ & 0.046 \\
$\begin{array}{l}\text { Coffee consumption > 3 cups/day vs. } \\
\text { less (referent) }\end{array}$ & 0.3 & $(0.1-1.0)$ & 0.051 \\
Lifestyle-related risk factors and V VF & & & $0.001^{*}$ \\
Low $V_{\text {LF (0-25\%) vs. Moderate or high }}$ & 3.3 & $(1.2-9.0)$ & 0.018 \\
(25-100\%) (referent) & & & \\
Low PA vs. moderate to high (referent) & 3.1 & $(1.1-8.5)$ & 0.028 \\
TUG $\geq 11$ s vs. less (referent) & 3.1 & $(1.0-8.9)$ & 0.042 \\
\hline
\end{tabular}

Odds ratios (OR) are calculated compared to the NF group. TUG "Timed Up \& Go" test, PA physical activity, $\mathrm{Cl}$ confidence interval. The number of subjects in the analyses was Hip Fx $n=18$, NF $n=296$. 'Age, BMI, TUG, PA, hypertension, coffee consumption, and smoking were included in the analysis to form the best model, ${ }^{2}$ The best model after including $\mathrm{V}_{\mathrm{LF}}$ in the analysis, ${ }^{*} \mathrm{p}$-value for the full model. the femoral neck BMD here was 2.11. Damilakis et al. [15] found no difference using the Omnisense device in the tibial SOS of healthy subjects and subjects with osteoporotic fracture. Nevertheless, they reported increased osteoporotic fracture ORs for ultrasound measurements on the radius and phalanx (ORs between 1.7 and 2.7). In other studies with an Omnisense device, SOS measured on the radius has been shown to discriminate subjects with hip fracture from controls with no fractures (ORs varying between 1.9 and 2.7) [16-18]. Another axial transmission QUS device, Myriad Soundscan (Myriad Ultrasound systems, Israel) uses a center frequency of $250 \mathrm{kHz}$ which is closer to that used in this study. Using this device, Stegman et al. [19] reported a low-energy appendicular fracture OR of 1.4 for the tibial SOS. This observation is in good agreement with the present study, where we found a similar trend in the retrospective part of the study. Augat et al. [20] found an increased OR of 1.7 for the tibial SOS of subjects who sustained hip fracture compared to non-fracture controls. The corresponding OR for the femoral neck BMD was 3.5 in their study. This SOS OR is somewhat lower than those observed in the present study for hip fractures. Also, Talmant et al. [21] studied the fracture discrimination ability of a $1 \mathrm{MHz}$ bidirectional ultrasonometer. They reported a fracture OR of 1.8 for the radius SOS and of 2.1 for the femoral neck BMD. Direct comparison between the ultrasound methods used is difficult due to differences in the ultrasound methodology and measurement setup. Also, the bone site and type of fracture, as well as the study populations, affect the results. However, the majority of the studies imply that axial transmission ultrasound is capable of assessing fracture risk.

Some studies have assessed the combining clinical risk factors and QUS parameters [22-24]. In the current study low $V_{L F}$ remained a significant risk factor for hip fracture when included in the lifestyle-related risk factor model observed in our previous study with the same population [9]. However, the lifestyle-related risk factors were collected at baseline whereas QUS measurements were made at eight 
years from baseline. Thus, the results need to be confirmed in future prospective studies.

In the present study ultrasound velocity was measured at mid-tibia. Even though osteoporosis is a systemic disease, the degree of changes in bone structure varies between bone sites. In weight-bearing sites (e.g. the tibia) bone loss is not as big as in non-weight-bearing sites (e.g. the radius and phalanx) [25]. Thus, even if the tibia is an easily accessible site for axial ultrasound measurements, it may not be the most responsive site to osteoporotic changes. Recently, we have reported that LF axial-transmission ultrasound in the radius is able to retrospectively discriminate postmenopausal women with fractures from age-matched controls with no fractures using an improved version of the LF ultrasound device used here [26].

The strength of the present study was the use of a population-based cohort of older women. The other strength was the relatively long follow-up time before and after the bone measurements. However, this study also had some limitations. One major limitation was the limited measurement precision of the current prototype device. The bulky mechanical scanning setup limits the positioning accuracy and does not enable proper correction for the impacts of overlying soft tissue [8]. As a result, the in vivo precision $\left(\mathrm{CV}_{\mathrm{rms}}\right)$ was limited. During the follow-up period of the study, significant mechanical improvements were implemented in the device, and a $\mathrm{CV}$ of $0.5 \%$ could be achieved with the latest device version $[5,26]$. Obviously, this valuable information available after the device improvement cannot retrospectively improve the quality of the results presented here. The other limitation is the retrospective nature of the study. It is possible that the fracture events before the measurements caused the changes in bone properties (e.g. via altered loading conditions) and affected on outcome of the measurement. Also, the number of hip fractures was relatively low, which significantly limited the statistical reliability of the results. Additionally, a minor limitation was the lack of reference data for young and healthy population, which disabled the determination of the T-score. Instead, we used quartiles to define the subjects with low $\mathrm{V}_{\mathrm{LF}}$ values.

\section{Conclusions}

In conclusion, decreased low-frequency ultrasound velocity was associated to increased hip fracture risk despite the limited measurement precision. The results reported here can be used to further improve the measurement precision of the method so as to reliably predict future fractures. To this end carefully planned follow-up studies are needed.

\section{Competing interests}

The authors declare that they have no competing interests.

\section{Authors' contributions}

MM participated in the fracture data collection, carried out the main analyses, and drafted the manuscript. PM participated in the analyses and interpretation of ultrasound data and manuscript writing. JT and PP made a contribution to the design of the study and revising the manuscript. RK and TJ participated in study conception and design, data interpretation and made substantial contributions to the manuscript. RK also participated significantly to collection of lifestyle-related risk factors data. All authors have read, revised, and given their final approval of the version to be published.

\section{Acknowledgements}

The work done is a part of the Osteoporotic Fracture Risk study supported by the Finnish Funding Agency for Technology and Innovation (Tekes, projects no. 40463/05, 40403/06). The work was also supported by the Academy of Finland. MM was supported by Tauno Tönning Foundation and Finnish Cultural Foundation.

\section{Author details}

${ }^{1}$ Department of Medical Technology, University of Oulu, Institute of Biomedicine, PO Box 5000, FI-90014 Oulu, Finland. ${ }^{2}$ Infotech Oulu, University of Oulu, Oulu, Finland. ${ }^{3}$ Department of Physics, University of Jyväskylä, Jyväskylä, Finland. ${ }^{4}$ Department of Sports and Exercise Medicine, Oulu Deaconess Institute, Oulu, Finland. ${ }^{5}$ Institute of Health Sciences, University of Oulu, Oulu, Finland. ${ }^{6}$ Medical Research Center Oulu, Oulu University Hospital and University of Oulu, Oulu, Finland. ${ }^{7}$ Department of Diagnostic Radiology, Oulu University Hospital, Oulu, Finland.

Received: 28 August 2013 Accepted: 10 June 2014 Published: 16 June 2014

\section{References}

1. Kanis JA, Oden A, Johansson H, Borgström F, Ström O, McCloskey E: FRAX and its applications to clinical practice. Bone 2009, 44(5):734-743.

2. Glüer CC: A new quality of bone ultrasound research. IEEE Trans Ultrason Ferroelectr Freq Control 2008, 55(7):1524-1528.

3. Marín F, González-Macías J, Díez-Pérez A, Palma S, Delgado-Rodríguez M: Relationship between bone quantitative ultrasound and fractures: a meta-analysis. J Bone Miner Res 2006, 21(7):1126-1135.

4. Lewiecki EM, Compston JE, Miller PD, Adachi JD, Adams JE, Leslie WD, Kanis JA, Moayyeri A, Adler RA, Hans DB, Kendler DL, Díez-Pérez A, Krieg MA, Masri BK, Lorenc RR, Bauer DC, Blake GM, Josse RG, Clark P, Khan AA, FRAX ${ }^{\circledast}$ Position Development Conference Members: Official Positions for FRAX ${ }^{\circledast}$ Bone Mineral Density and FRAX ${ }^{\circledast}$ simplification from Joint Official Positions Development Conference of the International Society for Clinical Densitometry and International Osteoporosis Foundation on FRAX ${ }^{\oplus}$. J Clin Densitom 2011, 14(3):226-236.

5. Kilappa V, Moilanen P, Xu L, Nicholson PH, Timonen J, Cheng S: Low-frequency axial ultrasound velocity correlates with bone mineral density and cortical thickness in the radius and tibia in pre- and postmenopausal women. Osteoporos Int 2011, 22(4):1103-1113.

6. Moilanen P, Nicholson PH, Kärkkäinen T, Wang Q, Timonen J, Cheng S: Assessment of the tibia using ultrasonic guided waves in pubertal girls. Osteoporos Int 2003, 14(12):1020-1027.

7. Nicholson PH, Moilanen P, Kärkkäinen T, Timonen J, Cheng S: Guided ultrasonic waves in long bones: modelling, experiment and in vivo application. Physiol Meas 2002, 23(4):755-768.

8. Määttä M, Moilanen $\mathrm{P}$, Nicholson $\mathrm{P}$, Cheng $\mathrm{S}$, Timonen J, Jämsä T: Correlation of Tibial Low-Frequency Ultrasound Velocity with Femoral Radiographic Measurements and BMD in Elderly Women. Ultrasound Med Biol 2009, 35(6):903-911.

9. Määttä M, Terho E, Jokinen H, Pulkkinen P, Korpelainen J, Heikkinen J, Keinänen-Kiukaanniemi S, Jämsä T, Korpelainen R: Lifestyle factors and site-specific risk of hip fracture in community dwelling older women a 13-year prospective population-based cohort study. BMC Musculoskelet Disord 2012, 13(1):173.

10. Korpelainen R, Korpelainen J, Heikkinen J, Väänänen K, Keinänen-Kiukaanniemi S: Lifestyle factors are associated with osteoporosis in lean women but not in normal and overweight women: a population-based cohort study of 1222 women. Osteoporos Int 2003, 14(1):34-43.

11. Podsiadlo D, Richardson S: The timed "Up \& Go": a test of basic functional mobility for frail elderly persons. J Am Geriatr Soc 1991, 39(2):142-148. 
12. Orgee JM, Foster H, McCloskey EV, Khan S, Coombes G, Kanis JA: A precise method for the assessment of tibial ultrasound velocity. Osteoporos Int 1996, 6(1):1-7.

13. Report of a WHO Study Group: Assessment of fracture risk and its application to screening for postmenopausal osteoporosis. World Health Organ Tech Rep Ser 1994, 843:1-129.

14. Nguyen TV, Center JR, Eisman JA: Bone mineral density-independent association of quantitative ultrasound measurements and fracture risk in women. Osteoporos Int 2004, 15(12):942-947.

15. Damilakis J, Papadokostakis G, Vrahoriti H, Tsagaraki I, Perisinakis K, Hadjipavlou A, Gourtsoyiannis N: Ultrasound velocity through the cortex of phalanges, radius, and tibia in normal and osteoporotic postmenopausal women using a new multisite quantitative ultrasound device. Invest Radiol 2003, 38(4):207-211.

16. Hans D, Srivastav SK, Singal C, Barkmann R, Njeh CF, Kantorovich E, Glüer CC, Genant HK: Does combining the results from multiple bone sites measured by a new quantitative ultrasound device improve discrimination of hip fracture? J Bone Miner Res 1999, 14(4):644-651.

17. Hans D, Genton L, Allaoua S, Pichard C, Slosman DO: Hip fracture discrimination study: QUS of the radius and the calcaneum. J Clin Densitom 2003, 6(2):163-172.

18. Weiss M, Ben-Shlomo A, Hagag P, Ish-Shalom S: Discrimination of proximal hip fracture by quantitative ultrasound measurement at the radius. Osteoporos Int 2000, 11(5):411-416.

19. Stegman MR, Heaney RP, Travers-Gustafson D, Leist J: Cortical ultrasound velocity as an indicator of bone status. Osteoporos Int 1995, 5(5):349-353.

20. Augat $P$, Fan B, Lane NE, Lang TF, LeHir P, Lu Y, Uffmann M, Genant HK: Assessment of bone mineral at appendicular sites in females with fractures of the proximal femur. Bone 1998, 22(4):395-402.

21. Talmant M, Kolta S, Roux C, Haguenauer D, Vedel I, Cassou B, Bossy E, Laugier P: In vivo performance evaluation of bi-directional ultrasonic axial transmission for cortical bone assessment. Ultrasound Med Biol 2009, 35(6):912-919.

22. Durosier C, Hans D, Krieg MA, Ruffieux C, Cornuz J, Meunier PJ, Schott AM: Combining clinical factors and quantitative ultrasound improves the detection of women both at low and high risk for hip fracture. Osteoporos Int 2007, 18(12):1651-1659.

23. Karjalainen JP, Riekkinen O, Töyräs J, Hakulinen M, Kröger H, Rikkonen T, Salovaara K, Jurvelin JS: Multi-site bone ultrasound measurements in elderly women with and without previous hip fractures. Osteoporos Int 2012, 23(4):1287-1295.

24. Hans D, Durosier C, Kanis JA, Johansson H, Schott-Pethelaz AM, Krieg MA: Assessment of the 10-year probability of osteoporotic hip fracture combining clinical risk factors and heel bone ultrasound: the EPISEM prospective cohort of 12,958 elderly women. J Bone Miner Res 2008, 23(7):1045-1051.

25. Knapp KM, Blake GM, Spector TD, Fogelman I: Multisite quantitative ultrasound: precision, age- and menopause-related changes, fracture discrimination, and T-score equivalence with dual-energy $\mathrm{X}$-ray absorptiometry. Osteoporos Int 2001, 12(6):456-464.

26. Moilanen P, Määttä M, Kilappa V, Xu L, Nicholson PH, Alén M, Timonen J, Jämsä T, Cheng S: Discrimination of fractures by low-frequency axial transmission ultrasound in postmenopausal females. Osteoporos Int 2012, 24(2):723-730

\section{Submit your next manuscript to BioMed Central and take full advantage of:}

- Convenient online submission

- Thorough peer review

- No space constraints or color figure charges

- Immediate publication on acceptance

- Inclusion in PubMed, CAS, Scopus and Google Scholar

- Research which is freely available for redistribution

Submit your manuscript at www.biomedcentral.com/submit 